experiment. In addition, whereas Maxwell's Demon acts as a non-randomizer, achieving its impossible goal by biased sorting of particles, Ridley's central message is that Mendel's acts as a randomizer (of genetic information). The two demons have nothing in common. Mendel would surely have had no truck with demons; Ridley should have followed his lead.

The Cooperative Gene is the latest product of what might be called the 'Oxford School' of evolutionary biology, whose current major protagonists include Richard Dawkins, Alan Grafen and David Haig. Starting from the inclusive-fitness arguments of W. D. Hamilton, the Oxford School takes a 'gene's-eye view' of evolutionary problems, and prefers the logic and elegant mathematics of game theory to the messy algebra of classical population genetics. But Ridley's book makes it clear that this approach is more than a mere alternative to traditional ones. Population genetics takes Mendel's laws as a given and applies them to populations, but Ridley is asking a more profound question: why and how did genetic systems, including meiosis, evolve? Thus population genetics essentially addresses the effects of the underlying causes in which Ridley is interested. The Cooperative Gene showcases a new way of thinking about evolutionarybiology.

Ridley's logic is often beguiling, and he all too often commits the familiar Oxford School sin of being too easily satisfied by plausible speculation - if it looks kosher and sounds good, then it's good enough. Ironically, one of the few hypotheses championed by Ridley that is readily amenable to experimental testing - Alexey
Kondrashov's theory of the origin of sex has recently indeed been tested, and found wanting. Kondrashov suggested that sex evolved to shuffle deleterious mutations, thereby facilitating the survival of individuals with relatively few mutations and the selective elimination of individuals with many. The theory requires that overall mutation rates in sexual species should therefore exceed the critical one-per-genome-pergeneration threshold. However, a recent empirical study of mutation rates found that a substantial proportion of sexual species do not meet this criterion. Such troublesome facts notwithstanding, Ridley has written a marvellous book - one that brings the evolutionary analysis of genetic systems well and truly into the genome era.

Andrew Berry is at MCZ Laboratories, 26 Oxford Street, Cambridge, Massachusetts 02138, USA.

\section{To begin at the beginning}

\section{Stem Cell Biology}

edited by Daniel R. Marshak, Richard L.

Gardner and David Gottlieb

Cold Spring Harbor Laboratory Press: 2001. 540 pp. $\$ 115$

\section{Sean J. Morrison}

Most tissues contain a small pool of undifferentiated cells called stem cells, which have the capacity to renew themselves by cell division, proliferate extensively and give rise

\title{
Through the eye of the camera?
}

\section{A photographic reconstruction (right) of Vermeer's The Music Lesson (below) reveals that a camera obscura may have been a part of the artist's armoury. Vermeer's Camera: Uncovering the Truth Behind the Masterpieces by Philip Steadman (Oxford University

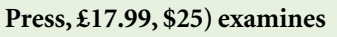 this controversial idea.}
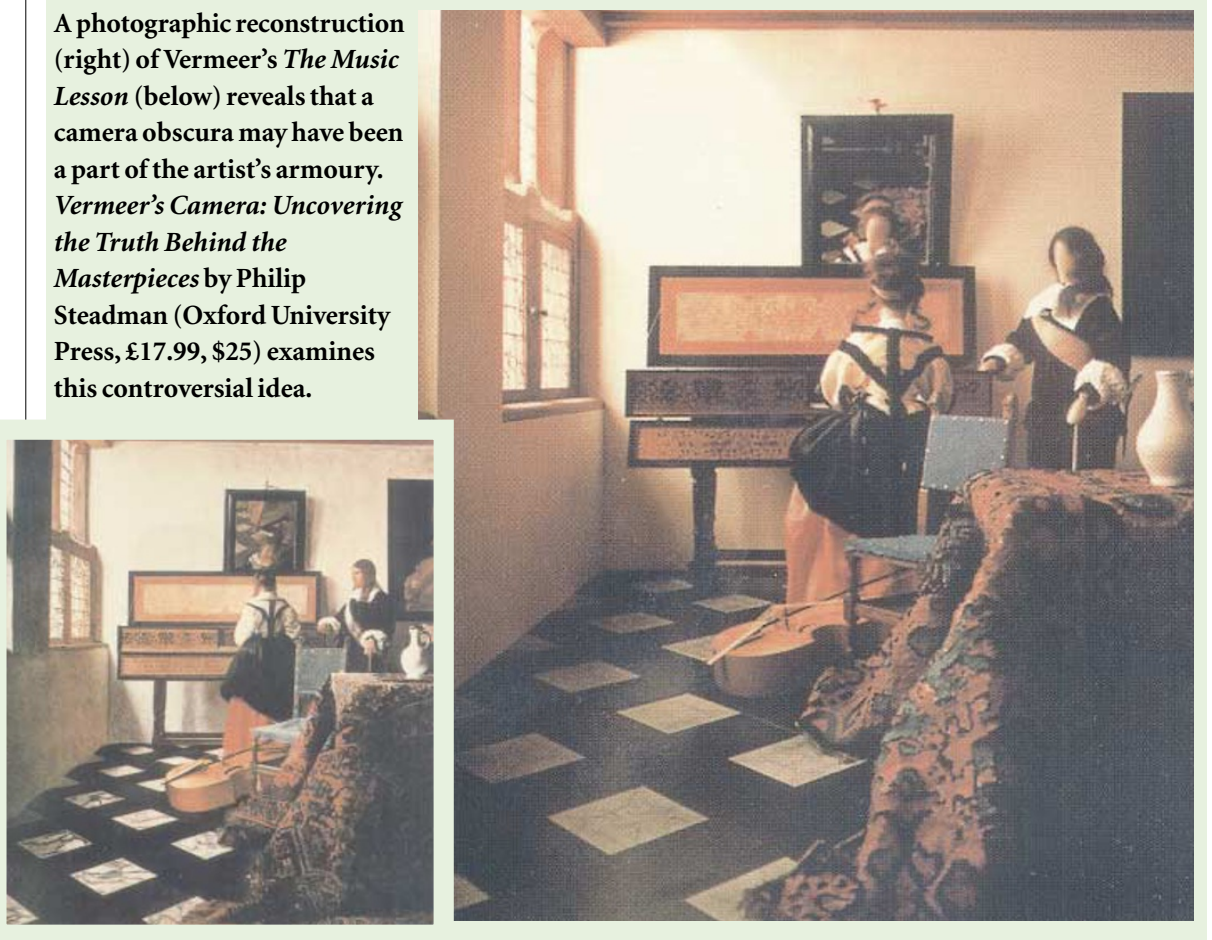

to many or all of the mature cell types found in the tissue. For example, embryonic stem cells of the inner cell mass of the early embryo give rise to all the cells of the body; haematopoietic stem cells in the bone marrow produce all blood cells; and neural stem cells produce different types of neurons and supporting glial cells. The current intense interest in stem cells lies in their potential to transform regenerative medicine, as well as the fact that recent advances have raised ethical issues related to the use of human fetal tissue as a source of stem cells.

The future of stem-cell biology will be to integrate what we know about stem cells in different tissues and at different times in development, so that we can both uncover common mechanisms of regulation and reveal the distinctions that guide stem cells to form different tissues. Yet most stem-cell biologists specialize in studying one type of stem cell from one tissue and have little basis on which to compare the properties of their cells with those from other systems.

Nonetheless, the similarities between stem cells in different systems have suffused the field with a belief that stem cells from different tissues will turn out to share many molecular properties. There is a widespread, but untested, expectation that different stem cells will use the same mechanisms to regulate common properties such as self-renewal and multipotency - the ability to form many different mature cell types. To test this expectation, we need to determine whether common genetic programmes are active in many different types of stem cells. Given the proclivity of stem-cell biologists to speculate unabashedly on the generality of their findings, some perspective is required to avoid myth-making.

Stem Cell Biology, edited by Daniel Marshak, Richard Gardner and David Gottlieb, will aid us in this task. This book considers the rich evolutionary and developmental complexity of stem cells in chapters ranging from yeasts to people, embryos to adults, and all three layers of the developing embryo - mesoderm, ectoderm and endoderm. The editors have done an excellent job of recruiting distinguished authors, including veteran leaders in the field such as Brigid Hogan and Austin Smith, and younger stars such as Markus Grompe. As a result, the book is strong on credibility and perspective. Each chapter is consistently written in a way that is accessible to the nonspecialist. This is therefore a very good book both for newcomers to stem-cell biology and for experts looking for new ideas by broadening their perspective.

In addition to the requisite chapters on haematopoietic, neural, epidermal, embryonic and the connective-tissue-producing mesenchymal stem cells, the book includes a general consideration of progenitor-cell biology, including chapters on cell-type 
switching in yeast and cell-cycle control. Equivalence groups are also discussed; these are clusters of undifferentiated cells with equivalent developmental potentials from which individual cells are selected to adopt specific fates. This discussion of the fundamental mechanisms that control proliferation and differentiation in yeast, flies and worms was a very perceptive addition, for the mechanisms identified in these model systems resonate with the questions asked of mammalian stem cells in later chapters. For example, an early chapter discussing the general phenomenon of senescence provided an interesting perspective on later discussions of the ageing of liver and haematopoietic stem cells.

Two types of stem cell figure most prominently in the book: pluripotent stem cells those able to give rise to all somatic cell types and germline cells - and haematopoietic stem cells. This is appropriate because, along with neural stem cells, they are the best characterized and most studied stem cells. Indeed, many of the hypotheses being tested in the context of liver and mesenchymal stem cells were conceived by analogy with haematopoietic stem cells.

Four chapters covering different aspects of the basic biology of haematopoietic stem cells give reasonably comprehensive coverage, although more systematic attention could have been paid to the different types of stem cells residing in different regions of the developing fetal haematopoietic system. These chapters provide an appreciation of the model on which much of stem-cell biology was conceptualized.

Similarly, an entire section of the book ( six chapters) covers different aspects of stem cells in early development. They include a look at male and female germline stem cells in Drosophila, and use excellent illustrations to demystify the complex cell biology of each system. A particularly nice feature is Minx Fuller's side-by-side description of germline stem cells in flies and mammals. A chapter on trophoblast stem cells - cells that eventually form most of the placenta - and three chapters on different types of potentially pluripotent stem cells compose the rest of the section. Together, they illustrate the diversity of pluripotent cell types and the parallels between them. Given the current controversies over the derivation and use of human pluripotent cell lines, these chapters would be timely reading for non-specialists participating in the debate.

If the future of basic stem-cell biology depends on our ability to integrate our understanding of different stem-cell systems, and if the future of applied stemcell biology depends on our ability to explain the field to non-specialists, then this book is a welcome step into the future.

Sean J. Morrison is in the Departments of Internal Medicine and Cell and Developmental Biology,
3215 CCGC, Howard Hughes Medical Institute, University of Michigan, Ann Arbor, Michigan 48109-0934, USA.

\section{Reactions of a chemical nature}

\section{Nationalizing Science: Adolphe Wurtz and the Battle for French Chemistry \\ by Alan J. Rocke

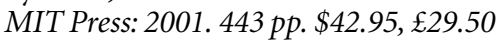 \\ Georges Bram}

A small street in Paris, and a street and a statue in Strasbourg, are now the only visible reminders of the distinguished nineteenthcentury French chemist Charles-Adolphe Wurtz - the man who famously wrote that "chemistry is a French science". Wurtz was a senator, a member of the French Academy of Sciences and a professor of organic chemistry at the Sorbonne. But he was not, as Alan Rocke explains, a 'star' of French science like Louis Pasteur, Marcellin Berthelot or Claude Bernard. Nevertheless, Wurtz's death, on 12 May 1884, received extensive coverage in the newspapers, and his students and colleagues wrote obituaries and biographical memoirs soon after. Studies on various aspects of Wurtz's work have been published more recently, but a comprehensive account was needed. This we now have from Alan Rocke in a book that will become a landmark in the study of the history of chemistry.

The author sets out his aim clearly - to provide a picture not only of the personal and intellectual life of Wurtz the man and scientist, but also of the social and political environment in which he lived, his daily working life and the evolution of scientific ideas.

Rocke gives us a good idea of the life and work of one of the major chemists of the nineteenth century. Many students passed through Wurtz's laboratory. They came from France, particularly Alsace, Wurtz's home region, and from other countries, and the lab was almost as important a school of chemistry as was the laboratory of Justus von Liebig in Giessen.

Wurtz was a tireless pioneer of the new theories that shaped organic chemistry. $\mathrm{He}$ promoted the ideas of Charles Gerhardt and Auguste Laurent who, in the first part of the nineteenth century, pioneered atomic theory in organic chemistry. And he later promoted the ideas of August Kekulé, who proposed the structure of the benzene ring. Completely convinced by atomic theory, Wurtz was opposed in this regard to many leading chemists such as Berthelot and Henri Sainte-Claire Deville, who belonged to the

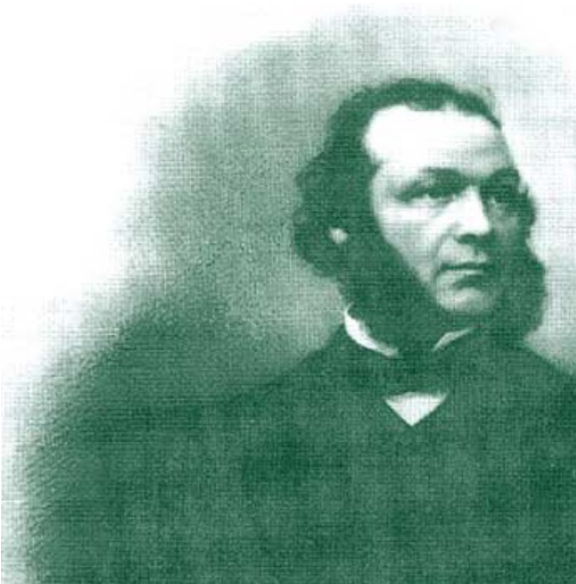

French pioneer: Wurtz tirelessly promoted the new theories that shaped organic chemistry.

traditional school, which believed that the intimate structure of matter was not a legitimate question.

Rocke also describes chemistry at the time of Wurtz, and the chemists Wurtz knew. A chapter apiece is devoted to Liebig and Jean-Baptiste Dumas, Wurtz's mentors. Another describes Berthelot, with whom Wurtz had a prolonged scientific fight over the question of atomic theory.

Rocke provides a valuable analysis of the decline of science in France in the second half of the nineteenth century - in particular, the decline of French chemistry in contrast to the rise of German chemistry. He discusses historians' ideas on this question and proposes some explanations. These include the adverse effects of French university rules; the custom for academics to hold many positions at the same time, leading young scientists to miss out on job opportunities; the low salaries of young scientists; and the poor equipment in French laboratories. He gives figures that clearly show the French deficit in science students: in 1876, the total number of students studying in the faculties of science in French universities was 293; this was equal to the number of students working for a scientific $\mathrm{PhD}$ at Liepzig University alone. In spite of the high quality of many of its teachers, French chemistry was in decline.

One cause of the decline, as Rocke explains, was that, until the end of the nineteenth century, the atomic basis of organic chemistry was only taught in French science faculties if individual teachers decided to 